\title{
Correction to: Design Patterns in .NET Core 3
}

\section{Dmitri Nesteruk}

\section{Correction to:}

Chapters 5, 6 \& 8 in: Dmitri Nesteruk, Design Patterns in .NET Core 3: Reusable Approaches in C\# and F\# for Object-Oriented Software Design https://doi.org/10.1007/978-1-4842-6180-4

The original version of the chapters $5,6 \& 8$ was inadvertently published with the introductory text placed at the end of incorrect chapters. The chapters affected are:

Chapter 5 (Prototype) - introductory text appears at end of Chapter 4

Chapter 6 (Singleton) - introductory text appears at end of Chapter 5

Chapter 8 (Bridge) - introductory text appears at end of Chapter 7

This has been corrected and the introductory text are placed at the correct chapters 5, 6 \& 8 .

The updated online version of these chapters can be found at https://doi.org/10.1007/978-1-4842-6180-4_5

https://doi.org/10.1007/978-1-4842-6180-4_6

https://doi.org/10.1007/978-1-4842-6180-4_8 